\title{
Biofilm Surface Density Determines Biocide Effectiveness
}

\author{
Sara Bas ${ }^{1}$, Mateja Kramer ${ }^{2}$ and David Stopar ${ }^{1 *}$ \\ ${ }^{1}$ Department of Food Science and Technology, Biotechnical Faculty, University of Ljubljana, Ljubljana, Slovenia, ${ }^{2}$ Lek d.d., \\ Sandoz, Ljubljana, Slovenia
}

High resistance of biofilms for chemical challenges is a serious industrial and medical problem. In this work a gradient of surface covered with biofilm has been produced and correlated to the effectiveness of different commercially available oxidative biocides. The results for thin Escherichia coli biofilms grown in rich media supplemented with glucose or lactose on glass or poly methyl methacrylate surfaces indicate that the effectiveness of hydrogen peroxide or chlorine dioxide and quaternary ammonium compounds is inversely proportional to the fraction of the surface covered with the biofilm. In areas where biofilm covered more than $90 \%$ of the available surface the biocide treatment was inefficient after 60 min of incubation. The combined effect of oxidant and surfactant increased the effectiveness of the biocide. On the other hand, the increased biofilm viscoelasticity reduced biocide effectiveness. The results emphasize differential biocide effectiveness depending on the fraction of the attached bacterial cells. The results suggest that biofilm biocide resistance is an acquired property that increases with biofilm

Edited by: Sara María Soto,

Barcelona Institute for Global Health (ISGlobal), Spain

Reviewed by: Jayapradha $R$

SASTRA University, India Efstathios D. Giaouris, University of the Aegean, Greece

${ }^{*}$ Correspondence: David Stopar david.stopar@bf.uni-lj.si

Specialty section: This article was submitted to Antimicrobials, Resistance and Chemotherapy, a section of the journal Frontiers in Microbiology

Received: 18 September 2017 Accepted: 24 November 2017 Published: 08 December 2017

Citation: Bas S, Kramer M and Stopar D (2017) Biofilm Surface Density Determines Biocide Effectiveness.

Front. Microbiol. 8:2443. doi: 10.3389/fmicb.2017.02443 maturation. The more dense sessile structures present lower log reductions compared to less dense ones.

Keywords: biofilms, E. coli, biocide, antimicrobial, surface coverage, viscoelasticity

\section{INTRODUCTION}

High resistance of biofilms for chemical challenges is a serious industrial and medical problem (Parsek and Fuqua, 2004). There are multiple mechanisms of bacterial resistance which vary with the bacteria present in the biofilm and the drug or biocide being applied (Videla, 2002). These mechanisms include physical or chemical reaction-diffusion barriers to antimicrobial penetration into the biofilm, slow growth of the biofilm cells due to nutrient limitation, activation of the general stress response, and the emergence of a biofilm-specific phenotype (Mah and O'Toole, 2001; Stewart, 2002). The individual bacteria in a biofilm may undergo physiological changes that improve resistance to biocides, such as induction of the general stress response (e.g., rpoSdependent process in Gram-negative bacteria), increased expression of multiple drug resistance pumps, activation of quorum-sensing systems, or changing profiles of outer membrane proteins (Mah and O'Toole, 2001). Furthermore, biofilms are rarely, as the name implies, continuous films of microbial material that cover large surface area but are uneven distributions of small and large patches of biofilm structures. It is generally assumed that biocide effectiveness in biofilms is approximately three orders of magnitude lower compared to bacterial suspensions (Mah and O’Toole, 2001). However, this might be misleading as biofilms are inherently heterogeneous structures and different parts of the biofilm may have significantly different susceptibilities for biocides. The effect of surface coverage heterogeneity in biofilms on biocide effectiveness has not been systematically studied yet. 
Biofilm heterogeneity spans different spatial scales (Karimi et al., 2015). Ultimately the effectiveness of the biocide will depend on the non-homogeneous distribution of individually attached cells. Antimicrobial agent must gain access to the heterogeneous biofilm structure. The rate of diffusion across a biofilm surface is dependent on the temperature, molecular size, and concentration gradient of the diffusing molecule (Watanabe et al., 1999; De Kee et al., 2005). Another important parameter is surface to volume ratio. The increased surface to volume ratio decreases time for the antimicrobial to diffuse through the volume. Under several environmental conditions biofilms may form thin flat structures with high surface to volume ratio, where vertical dimension of the biofilm is much smaller than the horizontal dimensions (Heydorn et al., 2000; Wimpenny et al., 2000; Young, 2006; Liu et al., 2015). In such cases the biofilm can be considered as a thin slab-like surface through which the antimicrobial agent diffuses. The two factors that are particular to diffusion through a slab-like structure are surface area and permeability, the latter being dependent on viscoelasticity (Peterson et al., 2015). It is hypothesized that in a thin biofilm structures the effectiveness of a biocide can be directly related to the surface area covered by the biofilm.

Because of their broad-spectrum activity against a variety of organic compounds oxidative biocides are often used in industry in control of biofilms (McDonnell and Russell, 1999). Oxidative biocides are proposed to have multiple targets within a cell which include peroxidation and disruption of membrane layers, oxidation of thiol groups, enzyme inhibition, oxidation of nucleosides, impaired energy production, disruption of protein synthesis and, ultimately, cell death (Finnegan et al., 2010). Often used biocides such as $\mathrm{H}_{2} \mathrm{O}_{2}$ and $\mathrm{ClO}_{2}$ that involve free radical formation can change amino acids, peptides, and proteins through hydrogen abstraction, electron transfer (oxidation or reduction), addition, fragmentation and rearrangement, dimerization, disproportionation, and substitution (concerted addition and elimination) (Finnegan et al., 2010). $\mathrm{H}_{2} \mathrm{O}_{2}$, per se, is considered a weak oxidant agent. However, it can easily cross the cellular membrane and reacts with transition metals, generating a highly reactive $\mathrm{OH}$ - that may oxidize and fragment the protein or DNA backbone (Hawkins and Davies, 2001). On the other hand, the primary mechanism for inactivation of the Escherichia coli with $\mathrm{ClO}_{2}$ is disruption of the protein synthesis pathway by inhibition of enzymes or interference with nucleic acid-amino acid complexes (Roller et al., 1980; Lin et al., 2016). Surfactants may be added to oxidizing agents to improve their antimicrobial effectiveness (Nakata et al., 2010). Among them, cationic surfactants such as quaternary ammonium compounds (e.g., CTAB) are frequently utilized for disinfection and sanitation purposes in a variety of fields, such as hospitals, food manufacturing, and pharmaceutical industry. Cationic surfactants disrupt cell membrane, inhibits the activity of MnSOD and SoxS, cause leakage of intracellular $\mathrm{K}^{+}$and other cell components, induce cell autolysis, and inhibit respiration (Nakata et al., 2010).

In this work, the impact of surface coverage on the biocide effectiveness was studied. To experimentally check this, a biofilm surface coverage gradient was produced and the effectiveness of different biocides was studied in glucose/glass and lactose/poly methyl methacrylate (PMMA) thin E. coli biofilms. Commercially available Klercide $\mathrm{B}$ and Klercide $\mathrm{C}$ biocides as well as lab made solution of $6 \% \mathrm{H}_{2} \mathrm{O}_{2}$ were used as biocides. A gradient in biofilm surface coverage has been created by growing biofilms in a Falcon tube with silica glass or PMMA slides positioned in a vertical direction in rich media supplemented with glucose or lactose under slow mixing conditions. A gradient of surface covered with biofilm formed from the air-water interphase to the bottom of the tube. The surface covered with biofilm was arbitrarily divided into three regions of high, medium, and low surface coverage. The antibacterial effectiveness of different oxidative biocides was tested. The results suggest a significant variability in antimicrobial effectiveness ranging from high effectiveness in area with low surface coverage to ineffective antimicrobial treatment in areas with high biofilm surface coverage. The biocide effectiveness was reduced with increased biofilm viscoelasticity.

\section{MATERIALS AND METHODS}

\section{Bacterial Strain and Media Preparation}

Escherichia coli MG1655, with plasmid gfp marker and resistance to kanamycin was grown overnight in LB Broth (Lennox, Laboratorios Conda) at $200 \mathrm{rpm}, 37^{\circ} \mathrm{C}$ for $16 \mathrm{~h}$. Two percent $(\mathrm{v} / \mathrm{v})$ of the overnight culture was transferred to fresh growth medium and grown to the mid of the exponential phase $\left(\mathrm{OD}_{600}\right.$ 0.5 ) and transferred to biofilm reactor. Biofilms were grown in the rich growth medium with $1.88 \mathrm{~g} / \mathrm{L} \mathrm{KH}_{2} \mathrm{PO}_{4}, 2.6 \mathrm{~g} / \mathrm{L} \mathrm{Na}_{2} \mathrm{HPO}_{4}$, $10.0 \mathrm{~g} / \mathrm{L}$ peptocomplex, and $5.0 \mathrm{~g} / \mathrm{L}$ yeast extract supplemented with either $22.0 \mathrm{~g} / \mathrm{L}$ of glucose for glass surface biofilms or $23.1 \mathrm{~g} / \mathrm{L}$ of lactose monohydrate for PMMA surface biofilms (Gomes, 2011).

\section{Biofilm Growth}

A simple batch culture biofilm reactor was used for biofilm growth (Król et al., 2011). Sterile microscope slides $25 \times 75 \mathrm{~mm}$ (glass or PMMA) were submerged in $25 \mathrm{~mL}$ of growth medium in a $50-\mathrm{mL}$ conical tube and incubated at $37^{\circ} \mathrm{C}$ on an orbital shaker at $50 \mathrm{rpm}$. To grow the biofilm, the tubes were inoculated with $50 \mu \mathrm{L}$ of the bacterial culture. The slides were transferred daily to tubes with a fresh growth medium. The loosely attached cells were not removed by rinsing before the transfer of each slide to the new medium. Biofilms were grown for 24, 48, and $72 \mathrm{~h}$. Prior to the inoculation the glass and PMMA slides were sonicated in a water bath sonicator (ASonic Pro Med 50) for 5 min with maximum power in $70 \%(\mathrm{v} / \mathrm{v})$ ethanol to remove impurities from the surface. Next the slides were treated with $6 \%(\mathrm{v} / \mathrm{v}) \mathrm{H}_{2} \mathrm{O}_{2}$ in water bath sonicator for $10 \mathrm{~min}$ with maximum power and rinsed with Milli-Q water (Ahmed and Russel, 1975). The nonattached cells were rinsed with $3 \mathrm{~mL}$ of PBS by pipette.

\section{Biofilm Microscopy}

Biofilms were observed after 24, 48, and $72 \mathrm{~h}$ under differential interference contrast (DIC) and brightfield microscopy. Slides were examined with Axio Observer Z1 epifluorescence microscope (Zeiss, Göttingen, Germany). The DIC and bright 
field images were observed using $10 \times$ and $20 \times$, NA 1.4, Zeiss lenses. Images were recorded with a coupled MRm Axiocam camera (Zeiss, Göttingen, Germany). To determine the fraction of the surface that was covered with biofilm, the glass and PMMA slides were air-dried, biofilm was flame fixed, stained with Gram's crystal violet solution (Sigma-Aldrich) for $15 \mathrm{~min}$, rinsed with distilled water, and air-dried prior to the observation. For each incubation time the slides with biofilms were divided vertically into 25 slabs, each $0.8 \mathrm{~mm}$ wide. The first slab was positioned at the biofilm water-air interphase. Brightfield images were recorded at a center of a given slab at $10 \times$ magnification and were analyzed with ImageJ to determine the fraction of the surface covered with the biofilm. Gray-scale intensity threshold was set automatically and then manually adjusted to exclude the background. As the biofilm surface coverage decreased from the interphase to the bottom of the tube each slab was arbitrarily classified into high, medium, or low covered biofilm surface. Micrographs which had between 90 and 100\% surface covered with biofilm were classified as high-density Zone I biofilms. In Zone II, biofilms from 10 to $90 \%$ of the available surface was covered with biofilm, in Zone III, less than $10 \%$ of the available surface was covered with biofilm structures. The length of the zone was determined with program AxioVision (Zeiss, Göttingen, Germany) with a length function. Next, the average fraction of surface covered with biofilm in a given zone was calculated. The total slide surface covered with biofilm $\left(\mathrm{mm}^{2}\right)$ in a given zone was calculated by

$$
A=f \cdot l \cdot b,
$$

where $f$ is the average fraction of surface covered with biofilm in a given zone, $l$ is the length of the zone, and $b$ is the width of the microscopic slide. DIC microscopy was used to determine thickness of the biofilm structures. Cells at the top of the biofilm have been focused next the object slide was moved to the clean spot and the total height of the biofilm was estimated. The height in the most dense Zone I did not exceed five cell layers. On average, the biofilms in Zone I were 2-3 layers thick. Thickness in Zones II and III was lower.

\section{Antimicrobial Treatment}

Biofilms grown for 24,48 , or $72 \mathrm{~h}$ were treated with $6 \%$ peroxide solution $\left(200 \mathrm{~mL}\right.$ of $30 \% \mathrm{H}_{2} \mathrm{O}_{2}$ mixed with $800 \mathrm{~mL}$ PBS), Klercide-CR Filtered Biocide B (Shield Medicare, Ecolab), and Premier Klercide-CR Sterile Filtered Biocide C (Shield Medicare, Ecolab). According to the manufacturer Klercide-CR Filtered Biocide B (abbreviated Klercide B in this study) is a sterile cleanroom biocide that consists of a blend of stabilized chlorine dioxide and a quaternary ammonium compound. It has a broad spectrum activity and possesses fast kill rates even under conditions of heavy organic soiling such as high covered surfaces with biofilms. Premier Klercide-CR Sterile Filtered Biocide C (abbreviated Klercide $\mathrm{C}$ in this study) is a blend of $6 \% \mathrm{H}_{2} \mathrm{O}_{2}$ and deionized water. For antimicrobial treatment the biofilms on glass or PMMA slides were rinsed with sterile PBS $(3 \mathrm{~mL}$ of PBS applied with pipette) and inserted in Falcon tubes with $30 \mathrm{~mL}$ of antimicrobial agent or $30 \mathrm{~mL}$ of $\mathrm{PBS}$ as a negative control. Biofilms were treated for 2, 20, and $60 \mathrm{~min}$ at room temperature. Next, slides were rinsed with $3 \mathrm{~mL}$ of PBS. BacLight Bacterial Viability Kit (SYTO 9/propidium iodide) was used for live/dead stain (Invitrogen, 2009). Cells with intact membrane emit green light due to SYTO 9 (Em. 480/Ex. 500), on the other hand cells with compromised membrane (dead cells) emit red light due to propidium iodide (Em. 536/Ex. 617). To each slide $20 \mu \mathrm{L}$ of stain mixture (1 $\mathrm{mM}$ SYTO and $6 \mathrm{mM}$ propidium iodide in PBS) was added and covered with opaque cover glass $(24 \times 60 \mathrm{~mm})$. The samples were stained for $30 \mathrm{~min}$ and observed with epifluorescence microscope (Zeiss, Göttingen, Germany) with appropriate settings for fluorescence (filters $38 \mathrm{HE}$ and 43HE).

Images were taken at $20 \times$ magnification. At least six randomly selected view fields per individual biofilm zone were examined and analyzed with Image to determine the number of live and dead cells. The threshold was set to discriminate bacterial fluorescence intensity from the background intensity. Next, the total fluorescence intensity for a view field was determined and the number of viable bacteria was calculated by dividing the total green fluorescence intensity with the intensity of the single bacterial cell. In total from 30,000 to 50,000 cells per view field were estimated in Zone I biofilm micrographs; 1000 to 30,000 cells were estimated in Zone II biofilm micrographs, and up to 1000 cells were estimated in Zone III biofilm micrographs. Similarly, the numbers of the dead bacteria were estimated from the red fluorescence. The fraction of the dead cells in a given zone was calculated as

$$
\% N_{\mathrm{d}}=\frac{N_{\mathrm{d}}}{N_{\mathrm{d}}+N_{\mathrm{l}}} \times 100,
$$

where $N_{\mathrm{d}}$ is the number of dead bacteria, $N_{1}$ is the number of live bacteria. The calculated fraction of dead bacteria in the negative control (PBS) was subtracted from the fraction of dead bacteria in the biofilm samples treated with different biocides.

\section{Planktonic Biocide Treatment}

Planktonic E. coli cells that were used for experiments with biocides were first incubated overnight in LB medium. Two percent $(\mathrm{v} / \mathrm{v})$ of the overnight culture was transferred to a fresh rich growth medium supplemented with glucose $(22.0 \mathrm{~g}$ of glucose, $1.88 \mathrm{~g} \mathrm{KH}_{2} \mathrm{PO}_{4}, 2.6 \mathrm{~g} \mathrm{Na} 2 \mathrm{HPO}_{4}, 10.0 \mathrm{~g}$ peptocomplex, and $5.0 \mathrm{~g}$ yeast extract solubilized in $1 \mathrm{~L}$ of distilled water) and incubated for $2.5 \mathrm{~h}$ to obtain cell density of approximately $10^{7} / \mathrm{mL}$. Next, the bacterial suspensions were either diluted or concentrated 100-fold. To concentrate or dilute bacterial suspensions the cultures were centrifuged at $8000 \times g$ for $5 \mathrm{~min}$ and pellets were re-suspended in appropriate lower or higher volume of PBS to obtain the final cell concentrations. Next, equal volumes of undiluted, diluted, and concentrated cultures were centrifuged at $8000 \times g$ for $5 \mathrm{~min}$ and the pellets were re-suspended in $300 \mu \mathrm{L}$ of antimicrobial agent or in $300 \mu \mathrm{L}$ PBS for a negative control. Cell suspensions were treated for $20 \mathrm{~min}$ and then centrifuged at $8000 \times g$ for $5 \mathrm{~min}$. The pellet was re-suspended in $300 \mu \mathrm{L}$ PBS and stained with LIVE/DEAD stain according to the manufacturer instructions. Ten microliters of stained cell suspension were transferred to microscopic glass 
slides and covered with cover glass $(20 \times 20 \mathrm{~mm})$. The fraction of the dead cells in planktonic phase was calculated as described for cells in biofilms.

\section{Biofilm Viscoelastic Properties}

To obtain enough material for rheological measurements $5 \mathrm{~mL}$ of overnight bacterial culture was evenly spread over agar solidified rich growth medium supplemented with glucose or lactose $\left(1.88 \mathrm{~g} \mathrm{KH}_{2} \mathrm{PO}_{4}, 2.6 \mathrm{~g} \mathrm{Na}_{2} \mathrm{HPO}_{4}, 10 \mathrm{~g}\right.$ peptocomplex, 5.0 g yeast extract, $20 \mathrm{~g}$ agar, and $22.0 \mathrm{~g}$ glucose or $23.0 \mathrm{~g}$ lactose monohydrate solubilized in $1 \mathrm{~L}$ of distilled water) in a glass petri dish (diameter $23 \mathrm{~cm}$ ) and incubated at $37^{\circ} \mathrm{C}$ for $24 \mathrm{~h}$. Dynamic rheological measurements were performed on a rotational rheometer Physica MCR 302 (Anton Paar, Graz, Austria) at $(20.00 \pm 0.01)^{\circ} \mathrm{C}$. The rheometer was equipped with the plate-plate measuring system (diameter $49.975 \mathrm{~mm}$ ). Approximately $0.7 \mathrm{~mL}$ of biofilm material was applied to the measuring system. Oscillatory amplitude sweep measurements were conducted at the angular frequency $\omega$ of $10^{-1} \mathrm{~s}$ and the strain $\gamma$ ranging from 0.001 to $1000 \%$ in 20 logarithmically spaced steps. Viscosity curves were measured at shear rates ranging from 0.01 to $1000^{-1} \mathrm{~s}$ in 40 logarithmically spaced steps with a time delay of $10 \mathrm{~s}$ between the successive measurements (Stojkovic et al., 2015). All rheological experiments were done in triplicates.

\section{Statistics}

The average values and standard errors were calculated. In experiments where the effectiveness of biocides was tested three independent biological experiments each made in triplicate were evaluated. For statistical analysis two-tailed $t$-test assuming equal variances were used.

\section{RESULTS}

\section{Biofilm Surface Coverage}

Two different biofilm systems were tested in this study: glucose/glass and lactose/PMMA. The E. coli biofilm grown on glass surface in the rich growth medium supplemented with glucose is shown in Figure 1A. The fraction of surface covered with biofilm decreased from the water-air interface to the bottom of the test tube producing a gradient in surface coverage in the vertical direction. The surface covered with biofilm was arbitrarily divided into three regions of high, medium, and low surface coverage. In Zone I biofilms formed a rather uniform high-density structures up to three layers thick which on average covered $95 \%$ of the available surface. Cells were embedded in the extracellular matrix structure. The length of Zone I increased after $72 \mathrm{~h}$ of incubation. There was a rather step gradient in surface coverage from Zone I to Zone III biofilm. In Zone II aggregates of attached bacteria were separated by individual cells attached to the glass surface. Cells in the aggregates were partially embedded in the extracellular matrix. In Zone III few microaggregates were present; mostly individual cells were attached to the surface that were not covered with extracellular matrix.
The biofilms grown on rich medium supplemented with lactose on PMMA were very different (Figure 1B). Bacteria formed well-developed dense biofilms only after $48 \mathrm{~h}$ of incubation. The length of the Zone I was significantly larger. Biofilms formed up to five layers thick continuous biofilm structures with smooth surface. The individual cells were embedded in the matrix. In Zone II bacterial cells produced aggregates of attached cells that form an interconnected biofilm network. Larger aggregates, two to three layers thick, were interspersed in the interconnected network and were covered with extracellular matrix. The number of large aggregates decreased in the vertical direction. Only few separated individual cells were observed in Zone II. The average surface density in the Zone II was higher compared to the respective zone of the glass surface. There was no Zone III biofilms after $48 \mathrm{~h}$ of incubation. The growth dynamics of the two biofilms is given in Table $\mathbf{1}$. The total area covered by the two biofilms increased during the incubation. When biofilms grew on PMMA surface in the rich medium supplemented with lactose significantly more biofilm structures formed compared to biofilms grown on glass surface supplemented with glucose. For instance, after $72 \mathrm{~h}$ of incubation the total surface covered with lactose grown biofilm structures on PMMA was $453.4 \mathrm{~mm}^{2}$ compared to $86.9 \mathrm{~mm}^{2}$ on glucose grown biofilm on glass surface.

\section{Biocide Effectiveness Anti-correlates with Biofilm Surface Coverage}

The results of live/dead assay on glucose grown biofilms on glass surface treated for $20 \mathrm{~min}$ with Klercide B are given in Figure 2. The red cells represent cells with compromised membrane after treatment with Klercide B. The fraction of the dead cells was highest in Zone III biofilms and decreased toward Zone I biofilms. Although most of the cells in Zone III were killed, there was nevertheless a significant number of green cells present after treatment with Klercide B. The results of the biocide treatments suggested that higher surface coverage anti-correlated with biocide effectiveness. To check this further various biocides and treatment durations were tested (Figure 3 ). The effectiveness of all biocides was inversely proportional to the biofilm surface coverage; it was low in Zone I and increased in Zones II and III. The most effective treatment was with Klercide B. The treatments with Klercide $\mathrm{C}$ or $\mathrm{H}_{2} \mathrm{O}_{2}$ gave comparable results. On average Klercide $\mathrm{C}$ slightly outperformed lab-made $\mathrm{H}_{2} \mathrm{O}_{2}$ biocide. The increased time of Klercide $\mathrm{B}$ treatment improved biocide effectiveness. However, the results for Klercide $\mathrm{C}$ and $\mathrm{H}_{2} \mathrm{O}_{2}$ were less clear. For example, in Zone I the duration of treatment with Klercide $\mathrm{C}$ and $\mathrm{H}_{2} \mathrm{O}_{2}$ increased the effectiveness of biocide; however, there was no significant effect in Zone III with prolonged duration of the treatment.

Overall the effectiveness of different biocides was much lower when biofilms were grown in the rich medium with lactose on PMMA (Figure 4). For all tested biocides the effectiveness was higher after $60 \mathrm{~min}$ of treatment as compared to $2 \mathrm{~min}$ of treatment. For example, in the case of Klercide B the effectiveness in Zone I increased twofold from $26 \%$ dead cells after $2 \mathrm{~min}$ of treatment to $50 \%$ after $60 \mathrm{~min}$, which is still considered 

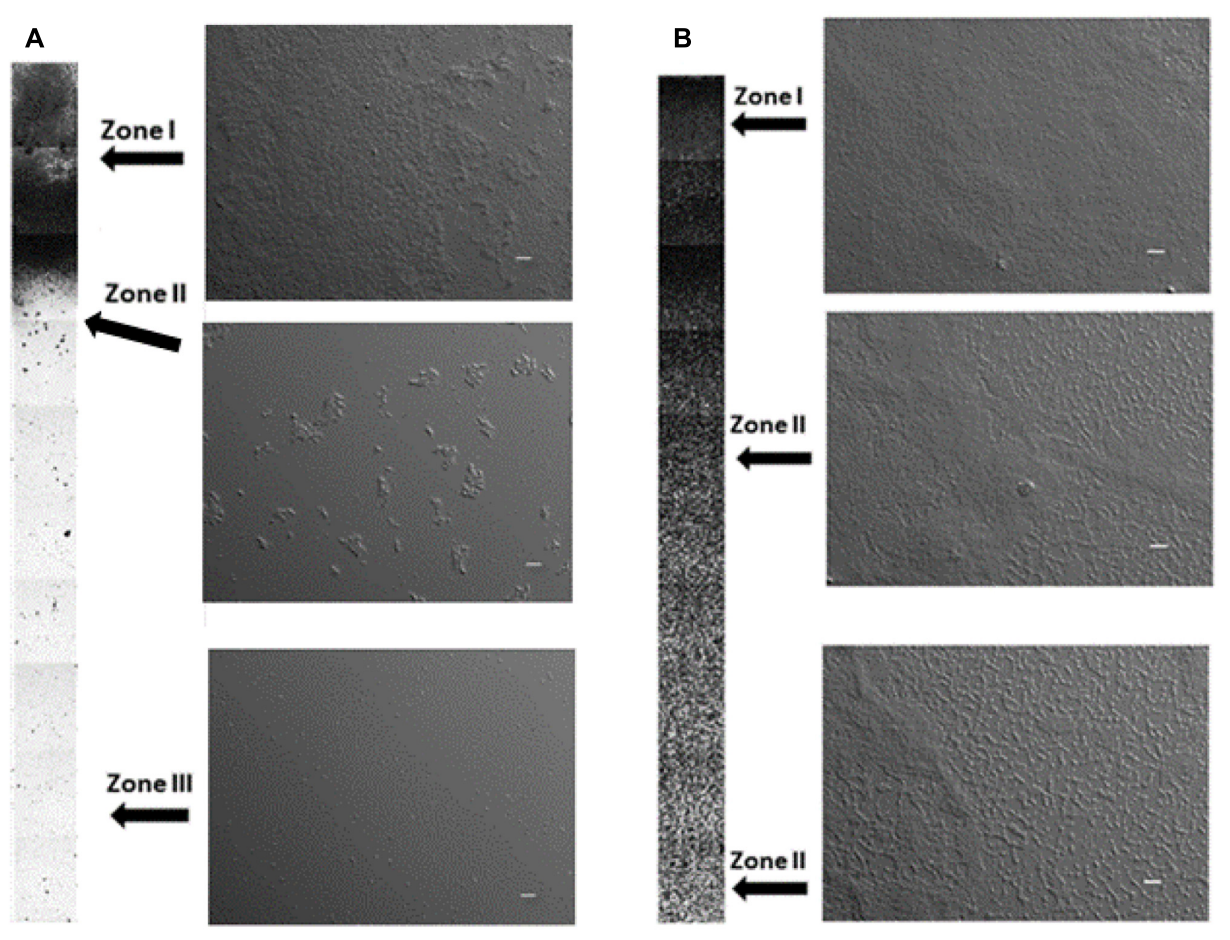

FIGURE 1 | Biofilms grown on glass surface in the rich medium supplemented with glucose (A), biofilms grown on PMMA surface in the rich medium supplemented with lactose (B) after $48 \mathrm{~h}$ of incubation. Zone I - arbitrarily designed high-density region where biofilm covered $90 \%$ or more of the available surface, Zone $\| \mathrm{I}$ - biofilm covered between 10 and $90 \%$ of the available surface, Zone III - biofilm surface coverage was less than $10 \%$. Columns represent a low magnification DIC micrographs taken every $0.8 \mathrm{~mm}$ in the vertical direction from the water-air interphase (total depth $20 \mathrm{~mm}$ ). Three representative higher magnification micrographs for different zones are shown on the right of the columns. Scale bar on micrographs represents $20 \mu \mathrm{m}$.

TABLE 1 | Surface area covered with biofilm after 24,48 , and $72 \mathrm{~h}$ of incubation of $E$. coli in rich growth media supplemented with glucose on glass surface or lactose on PMMA surfaces.

Biofilm covered surface $\left(\mathrm{mm}^{2}\right)$

\begin{tabular}{|c|c|c|c|c|c|c|c|c|}
\hline \multirow{2}{*}{$\begin{array}{l}\text { Medium and material } \\
\text { Time (hours) }\end{array}$} & \multicolumn{4}{|c|}{ Rich medium with glucose, glass } & \multicolumn{4}{|c|}{ Rich medium with lactose, PMMA } \\
\hline & Zone I & Zone II & Zone III & Total surface & Zone I & Zone II & Zone III & Total surfaces \\
\hline 48 & $34.86 \pm 2.04$ & $11.6 \pm 1.56$ & $2.60 \pm 0.28$ & 49.06 & $73.71 \pm 5.02$ & $192.96 \pm 10.15$ & 0 & 266.67 \\
\hline 72 & $36.19 \pm 1.55$ & $45.43 \pm 5.09$ & $5.33 \pm 0.73$ & 86.95 & $231.85 \pm 1.47$ & $221.55 \pm 5.08$ & 0 & 453.40 \\
\hline
\end{tabular}

The average values and standard errors are given $(n=9)$.

low for an effective biocide treatment. The effectiveness of biocides in lactose/PMMA biofilms was lower compared to glucose/glass biofilms. In both biofilm systems (glucose/glass and lactose/PMMA) the most effective treatment was with Klercide B.

\section{Biocide Effectiveness in Planktonic Suspensions}

The effectiveness of different biocides tested on planktonic exponentially grown E. coli suspensions are given in Figure 5A. The most effective was Klercide B. The effectiveness of biocides was larger in dilute planktonic cell suspensions (Figure 5B). The effectiveness at low cell densities (e.g., $10^{5}$ cells $/ \mathrm{mL}$ ) was comparable to biocide effectiveness in Zone III biofilms. If the density of the planktonic culture increased the effectiveness of the biocide decreased significantly and when the cell density was $10^{9}$ cells $/ \mathrm{mL}$ it was comparable to the biocide effectiveness in high-density Zone I biofilms.

\section{Viscoelasticity of E. coli Biofilms}

Although surface coverage in Zone I biofilms were approximately equal in glucose/glass and lactose/PMMA biofilms (95.3 and $93.8 \%$, respectively) and the thicknesses of the two biofilms were comparable, the effectiveness of the biocide treatments were lower in lactose/PMMA biofilms. In addition it took longer to obtain approximately the same killing effectiveness with Klercide B in lactose/PMMA biofilms in Zone I biofilms. This could be due to different diffusion rates of biocides in the 

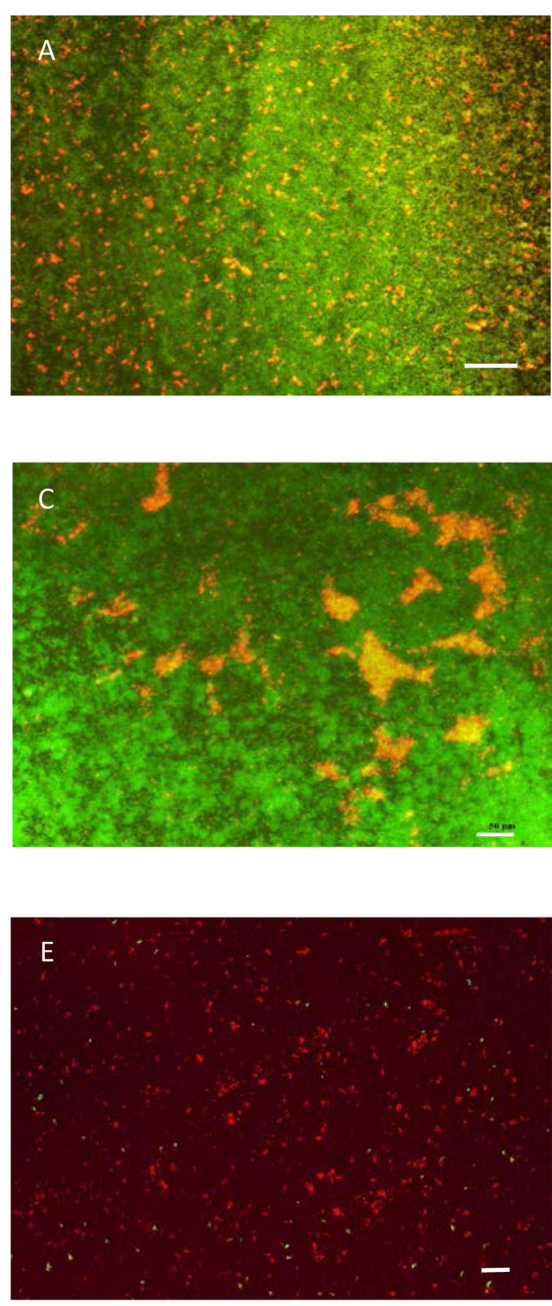
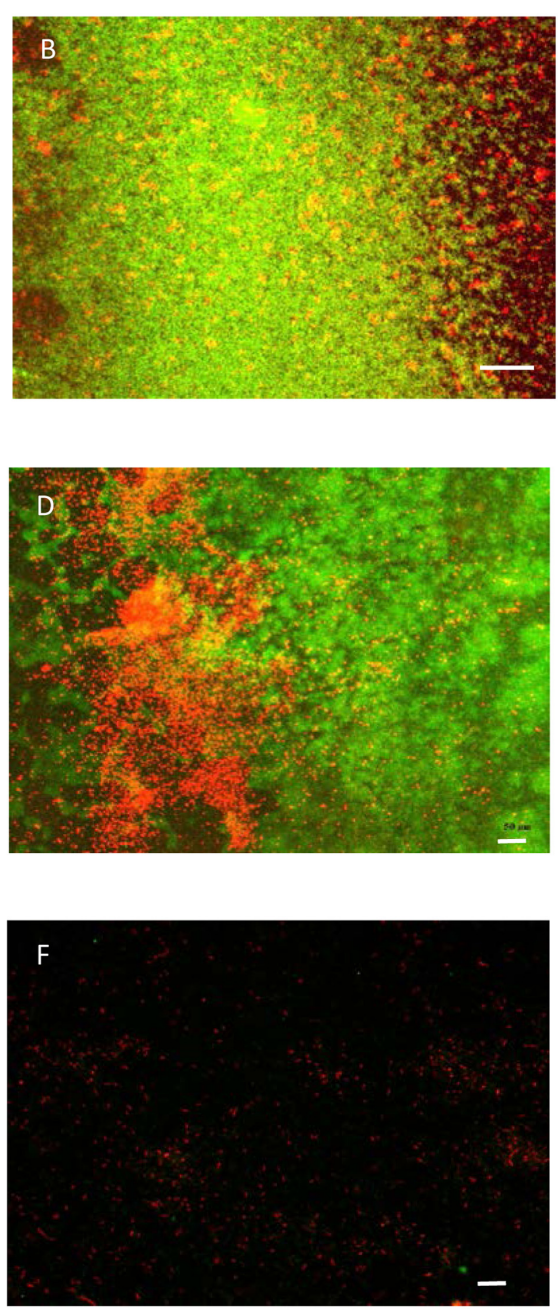

FIGURE 2 | The live/dead assay on cells in Zone I (A,B), Zone II (C,D), and Zone III (E,F) biofilms. Biofilms were grown for $48 \mathrm{~h}$ in rich growth medium supplemented with glucose on glass surfaces and treated with Klercide B for 20 min. Scale bars in (A) and (B) represent $100 \mu \mathrm{m}$, in other panels they represent $50 \mu \mathrm{m}$.

two biofilms. According to Stokes-Einstein diffusion equation $D=\left(k_{\mathrm{B}} T\right) /(6 \pi \eta a)$, where $D$ the is diffusion constant, $k_{\mathrm{B}}$ is the Boltzmann constant, $T$ is the temperature, $\eta$ is the viscosity, and $a$ the radius of a particle, slower diffusion at a given temperature and size of the diffusing molecule is a direct consequence of a more viscous environment. To check for this the viscosities of the two confluent biofilms grown on agar surface were measured. The viscosity curves of the E. coli biofilms grown on glucose or lactose rich medium are given in Figure 6. The viscosity curve for the biofilm grown on lactose was consistently higher at all shear rates tested (over five orders of magnitude). The viscosity curves of both biofilms indicate a strong pseudoplastic behavior typical of a biofilm behavior.

The two biofilms had different consistencies. The storage and loss moduli of biofilms grown in the rich medium with glucose or lactose are given in Figure 7. The behavior of the two biofilms is typical for viscoelastic gel materials. Both the storage modulus $\left(G^{\prime}\right)$ and the loss modulus $\left(G^{\prime \prime}\right)$ were higher in lactose biofilms compared to glucose biofilms. From oscillatory tests one can notice that the structure of the biofilm grown on glucose is more fragile and starts to break at lower shear stress than the biofilm grown on lactose. Also the flow point, when $G^{\prime}$ and $G^{\prime \prime}$ curves cross, is reached at a lower shear strain in glucose biofilms. This suggests that gel structure of the biofilm grown on lactose is stronger and more viscous which could explain lower effectiveness of biocides compared to glucose biofilms.

\section{DISCUSSION}

In this work the biocide effectiveness was correlated to the surface area covered by $E$. coli biofilms. In spite of extensive research of inadequate biocide effectiveness in biofilms, there are no systematic studies correlating biofilms surface area to biocide effectiveness. The obtained results imply a strong anti-correlation between the effectiveness of the biocide and the fraction of surface covered with the biofilm. Higher the fraction of the surface 


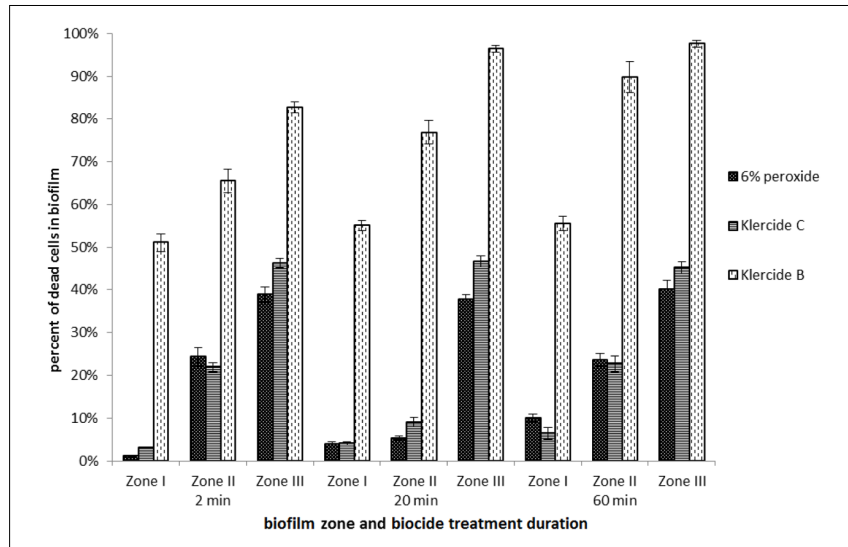

FIGURE 3 | Fraction of the dead cells in different biofilm zones. Biofilms of E. coli were grown in the rich medium with glucose on glass surface for $48 \mathrm{~h}$. Different biocides were added to for 2, 20, and $60 \mathrm{~min}$. The average values and standard errors are given $(n=9)$.

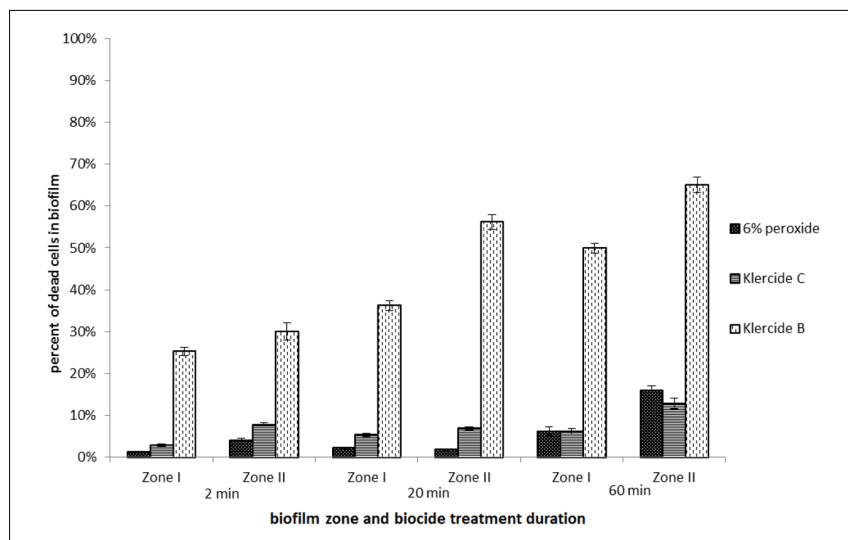

FIGURE 4 | Effectiveness of different biocides. Biofilms of $E$. coli grown in the rich medium supplemented with lactose on PMMA surface for $48 \mathrm{~h}$. Biocides were added for 2,20 , and $60 \mathrm{~min}$. The average values and standard errors are given $(n=9)$.

covered with the biofilm, lower the effect of the biocide. This was observed for all biocides tested.

Although there was a clear anti-correlation of biocide effectiveness with biofilm surface coverage this alone cannot explain the results obtained. The different biocide effectiveness in the three zones is further modified by different concentrations of the extracellular matrix present. Cells in Zone I were covered with extracellular matrix, which increases their resistance to the oxidative biocides. On the other hand, in Zone III individual cells were not embedded in the extracellular matrix. These cells were most susceptible for the action of biocides. It is, however, questionable if cells attached to the surface in Zone III can be considered biofilm structures. Although cell attachment is a necessary condition it is not a sufficient condition for mature biofilm formation. The results suggest that biofilm biocide resistance is an acquired property that increases with biofilm maturation. The antibacterial effect in Zone III was comparable to the effect of the biocide in low density E. coli planktonic cultures.
A

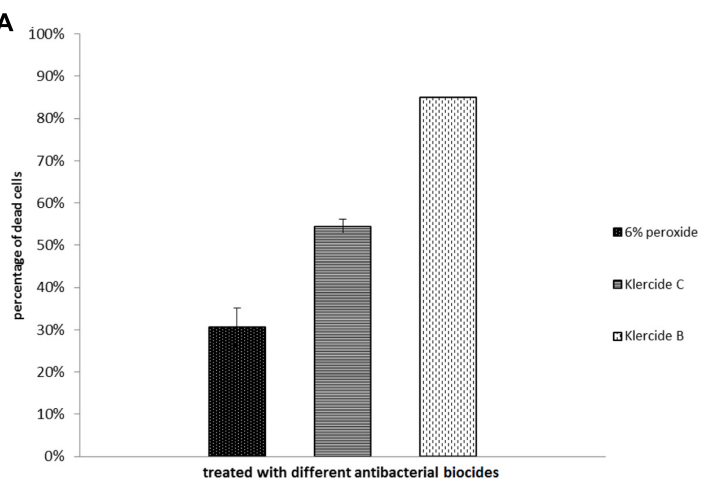

B

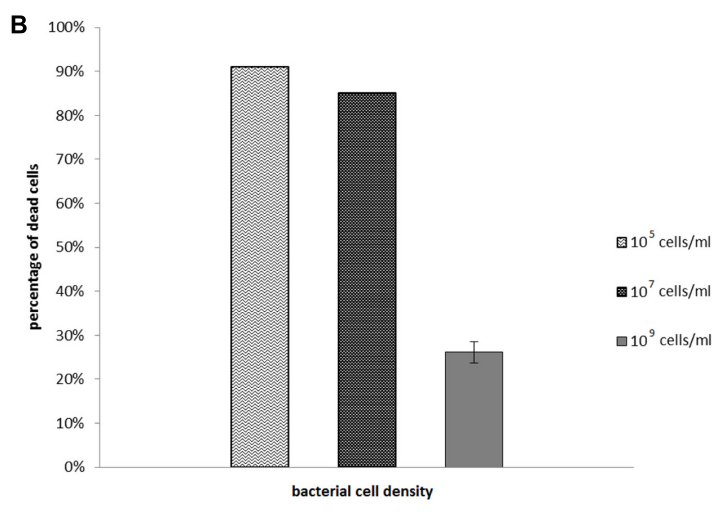

FIGURE 5 | Fractions of the dead cells in planktonic culture of E. coli grown in the rich medium with glucose. Cells were grown to cell density of $10^{7}$ cells $/ \mathrm{mL}$ and treated with different biocides (A). Cells treated with Klercide B at different cell densities (B). Bacterial suspensions with different cell density were treated with biocides for $20 \mathrm{~min}$. The average values and standard errors are given $(n=9)$.

In contrast in high-density planktonic cultures the effectiveness of biocides was similar to high-density Zone I biofilms. Similar observations have been made by Kirby et al. (2012) who showed that high-density planktonic growth stimulates the same level of resistance to antimicrobial agents as adherent biofilms. The effectiveness of biocides was time dependent and increased with the duration of the biocide treatment (Figures 3, 4).

Structural properties of biofilms are to a large extent determined by the environment in which biofilms grow. For example, changing organic carbon composition in the growth medium of Bacillus subtilis had a dramatic impact on the extracellular matrix production and composition (Dogsa et al., 2013). Different extracellular matrix composition will in turn affect viscosity of the extracellular matrix and consequently biocide effectiveness (Rühs et al., 2013). It has been suggested that viscous environment can induce tolerance to antibiotics within planktonic bacterial populations to the levels found in biofilms. For example, Pseudomonas aeruginosa and Staphylococcus epidermidis exhibited enhanced tolerance to biocides when grown in 30\% poloxamer gel (Gilbert et al., 1998; Wirtanen et al., 1998). Similarly, increased tolerance of Pseudomonas and Candida to antimicrobials in viscous media supplemented with poly(vinylpirrolidone) (PVP) was 


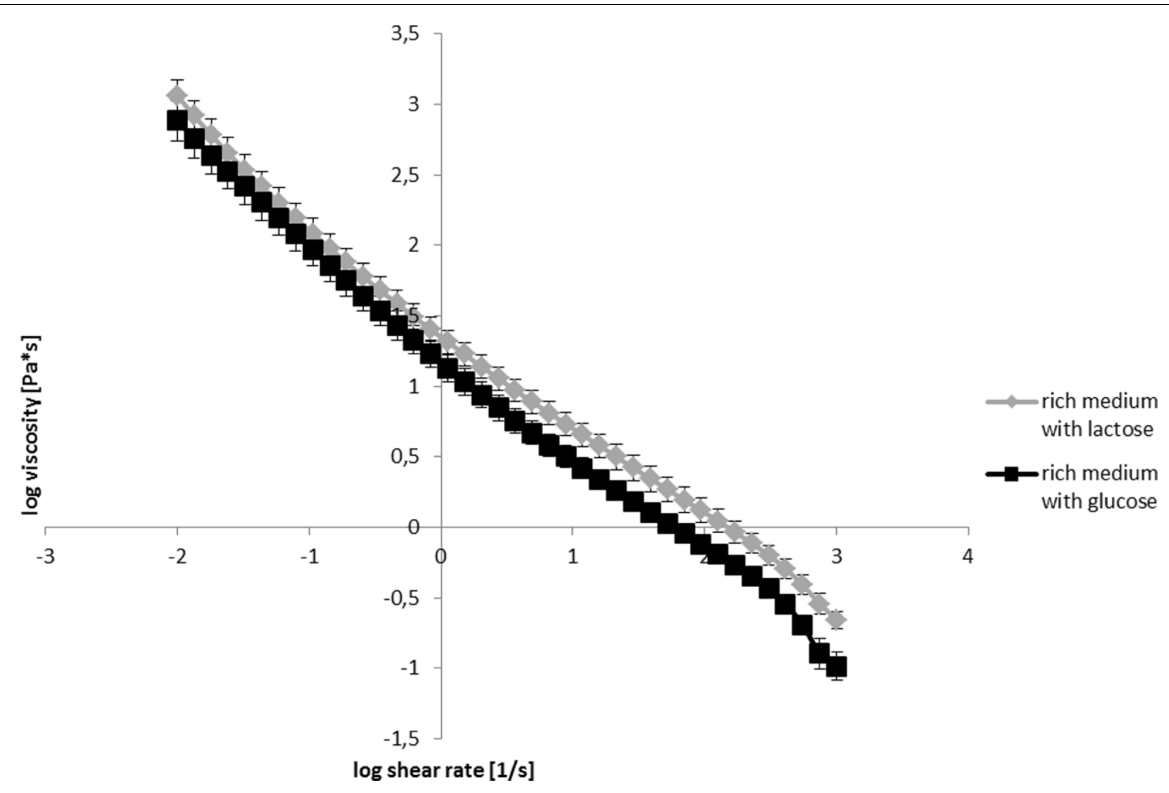

FIGURE 6 | Viscosity curves for the confluent biofilm of E. coli grown in the rich medium with glucose or lactose after $24 \mathrm{~h}$ of incubation on agar plates.

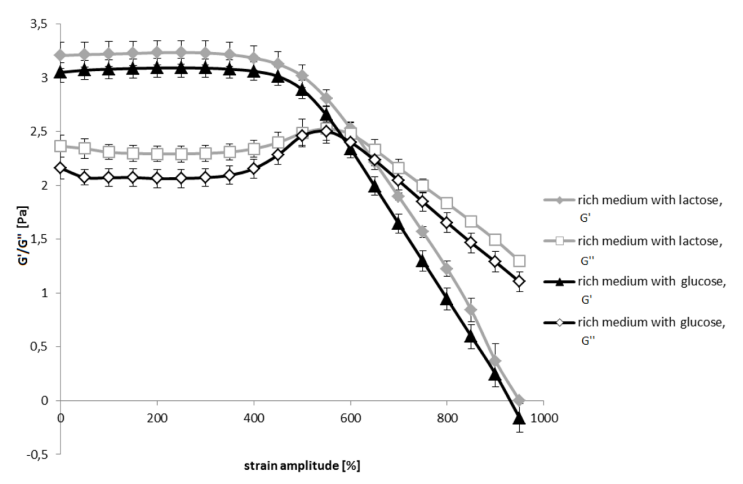

FIGURE 7 | Viscoelastic moduli $\mathrm{G}^{\prime}$ and $\mathrm{G}^{\prime \prime}$ as a function of strain amplitude for the confluent $E$. coli biofilms grown in the rich medium supplemented with glucose or lactose after $24 \mathrm{~h}$ of incubation on agar plates.

observed (Chan, 1998; Kostenko et al., 2007). The results of the biofilm viscoelastic measurements of biofilms grown on glucose or lactose on agar surface (Figures 6, 7) suggest the role of carbon source in structuring the extracellular matrix. The lactose grown biofilms which produced stronger gels and had higher viscosities may be less susceptible for biocide tratment.

All tested biocides contained oxidants (chlorine dioxide or $\mathrm{H}_{2} \mathrm{O}_{2}$ ). The presence of biofilm extracellular matrix material will reduce the effectiveness of biocides that rely solely on oxidative stress such as Klercide $\mathrm{C}$ or $6 \% \mathrm{H}_{2} \mathrm{O}_{2}$ solutions (Finnegan et al., 2010). It is expected that in biofilms with larger surface coverage (e.g., Zone I), where more extracellular matrix is produced, this will be more pronounced. Consistently, the effectiveness of Klercide $\mathrm{C}$ and $6 \% \mathrm{H}_{2} \mathrm{O}_{2}$ was lowest in high-density biofilms. The most effective antibacterial agent was Klercide B which combined the oxidative damage induced by chlorine dioxide with surface activity of CTAB. This was particularly noticeable in biofilms with large surface area. For example, in Zone I Klercide B was 22 -fold more effective than Klercide C, it was 4.5 -fold more effective in Zone II, whereas in Zone III it was only twofold more effective after 2 min of treatment. This further emphasizes a differential effectiveness of biocides in small and large aggregates of biofilms.

\section{CONCLUSION}

The results clearly indicate that oxidative biocides work efficiently on a single attached cell or small aggregate of attached cells, but significantly less on biofilms that cover large surface areas. Biofilm biocide resistance increases with maturation which correlates with extracellular matrix production. Thus, more dense attached structures present lower log reductions (i.e., lower percentages of dead cells) compared to less dense ones. The observations further suggest that changing viscoelastic properties of biofilms may allow for a better diffusion and therefore increased effectiveness of biocide treatment, a hypothesis worth further testing. For applications of biocides in biofilm control it might therefore be beneficial to reduce the density of the biofilm prior to the biocide application. This could be achieved for example by mechanical scraping, using scrub brushes, increased flow shear stress, or laser activated irrigation, which will reduce the size and cohesiveness of the biofilm aggregate prior to the application of the biocide. In reporting the efficiency of the biocide treatments the density of the biofilm (e.g., fraction of the surface covered by biofilms and/or cellular concentration) should be reported to ensure better reproducibility of the data in different laboratories. 


\section{AUTHOR CONTRIBUTIONS}

SB performed experiments, analysis, conducted the work, and was involved in designing of the work, writing, and interpretation of the data. MK was involved in designing of the work, interpretation of the data, and writing. DS was involved in designing of the work, interpretation of the data, writing, submission of the manuscript, and ensured that questions related to the accuracy or integrity of any part of the work are appropriately investigated and resolved.

\section{REFERENCES}

Ahmed, F. I. K., and Russel, C. (1975). Synergism between ultrasonic waves and hydrogen peroxide in the killing of micro-organisms. J. Appl. Microbiol. 39, 31-40. doi: 10.1111/j.1365-2672.1975.tb00542.x

Chan, W. (1998). The Role of Viscosity in Pseudomonas and Candida Phenotype Expression. Ph.D. thesis, University of Calgary, Calgary, AB.

Dogsa, I., Brloznik, M., Stopar, D., and Mandic-Mulec, I. (2013). Exopolymer diversity and the role of levan in Bacillus subtilis biofilms. PLOS ONE 8:e62044. doi: 10.1371/journal.pone.0062044

De Kee, D., Liu, Q., and Hinestroza, J. (2005). Viscoelastic (non-fickian) diffusion. Can. J. Chem. Eng. 83, 913-929. doi: 10.1002/cjce.5450830601

Finnegan, M., Linley, E., Denyer, S. P., McDonnell, G., Simons, C., and Maillard, J. Y. (2010). Mode of action of hydrogen peroxide and other oxidizing agents: differences between liquid and gas forms. J. Antimicrob. Chemother. 65, 2108-2115. doi: 10.1093/jac/dkq308

Gomes, L. C. (2011). Optimization of Cultivation Conditions for E. coli Biofilm Formation in Microtiter Plates. Master dissertation, Porto University, Porto, 1-99.

Gilbert, P., Jones, M. V., Allison, D. G., Heys, S., Maira, T., and Wood, P. (1998). The use of poloxamer hydrogels for the assessment of biofilm susceptibility towards biocide treatments. J. Appl. Microbiol. 85, 985-990. doi: 10.1111/j.13652672.1998.tb05262.x

Hawkins, C. L., and Davies, M. J, (2001). Generation and propagation of radical reactions on proteins. Biochim. Biophys. Acta 1504, 196-219. doi: 10.1016/ S0005-2728(00)00252-8

Heydorn, A., Nielsen, A. T., Hentzer, M., Sternberg, C., Givskov, M., Ersbøll, B. K., et al. (2000). Quantification of biofilm structures by the novel computer program COMSTAT. Microbiology 146, 2395-2407. doi: 10.1099/00221287146-10-2395

Invitrogen (2009). FilmTracer ${ }^{\mathrm{TM}}$ LIVE/DEAD ${ }^{\circledR}$ Biofilm Viability Kit. Molecular Probes. Carlsbad, CA: Invitrogen, 1-4.

Karimi, A., Karig, D., Kumar, A., and Ardekani, A. M. (2015). Interplay of physical mechanisms and biofilm processes: review of microfluidic methods. Lab Chip 15, 23-42. doi: 10.1039/c4lc01095g

Kirby, A. E., Garner, K., and Levin, B. R. (2012). The relative contributions of physical structure and cell density to the antibiotic susceptibility of bacteria in biofilms. Antimicrob. Agents Chemother. 56, 2967-2975. doi: 10.1128/AAC. 06480-11

Kostenko, V., Ceri, H., and Martinuzzi, R. J. (2007). Increased tolerance of Staphylococcus aureus to vancomycin in viscous media. FEMS Immunol. Med. Microbiol. 51, 277-288. doi: 10.1111/j.1574-695X.2007. 00300.x

Król, J. E., Nguyen, H. D., Rogers, L. M., Beyenal, H., Krone, S. M., and Top, E. M. (2011). Increased transfer of a multidrug resistance plasmid in Escherichia coli biofilms at the air-liquid interface. Appl. Environ. Microbiol. 77, 5079-5088. doi: 10.1128/AEM.00090-11

Lin, T., Hou, B., Wang, Z., and Chen, W. (2016). Inactivation of particle-associated E. coli with chlorine dioxide. Water Sci. Technol. Water Supply 17:ws2016121. doi: 10.2166/ws.2016.121

Liu, J., Prindle, A., Humphries, J., Gabalda-Sagarra, M., Asally, M., Lee, D. Y., et al. (2015). Metabolic codependence gives rise to collective oscillations within biofilms. Nature 523, 550-554. doi: 10.1038/nature 14660

\section{FUNDING}

This work was benefited from the support of the Slovenia Government via the National Research Agency [P4-0116(D)].

\section{ACKNOWLEDGMENT}

The authors would like to thank Iztok Dogsa for technical support with microscopy and rheology experiments.

Mah, T. F., and O'Toole, G. A. (2001). Mechanisms of biofilm resistance to antimicrobial agents. Trends Microbiol. 9, 34-39. doi: 10.1016/S0966-842X(00) 01913-2

McDonnell, G., and Russell, A. D. (1999). Antiseptics and disinfectants: activity, action, and resistance. Clin. Microbiol. Rev. 12, 147-179.

Nakata, K., Tsuchido, T., and Matsumura, Y. (2010). Antimicrobial cationic surfactant, cetyltrimethylammonium bromide, induces superoxide stress in Escherichia coli cells. J. Appl. Microbiol. 110, 568-579. doi: 10.1111/j.1365-2672. 2010.04912

Parsek, M. R., and Fuqua, C. (2004). Biofilms 2003: emerging themes and challenges in studies of surface-associated microbial life. J. Bacteriol. 186, 4427-4440. doi: 10.1128/JB.186.14.4427-4440.2004

Peterson, B. W., He, Y., Ren, Y., Zerdoum, A., Libera, M. R., Sharma, P. K., et al. (2015). Viscoelasticity of biofilms and their recalcitrance to mechanical and chemical challenges. FEMS Microbiol. Rev. 39, 234-245. doi: 10.1093/femsre/ fuu008

Roller, S. D., Olivieri, V. P., and Kawata, K. (1980). Mode of bacterial inactivation by chlorine dioxide. Water Res. 14, 635-641. doi: 10.1016/0043-1354(80) 90121-9

Rühs, P. A., Böni, L., Fuller, G. G., Inglis, R. F., and Fischer, P. (2013). In-situ quantification of the interfacial rheological response of bacterial biofilms to environmental stimuli. PLOS ONE 8:e78524. doi: 10.1371/journal.pone. 0078524

Stewart, P. S. (2002). Mechanisms of antibiotic resistance in bacterial biofilms. Int J. Med. Microbiol. 292, 107-113. doi: 10.1078/1438-4221-00196

Stojkovic, B., Sretenovic, S., and Stopar, D. (2015). Viscoelastic propreties of levanDNA mixtures important in microbial biofilm formation as determined by micro- and macrorheology. Biophys. J. 108, 758-765. doi: 10.1016/j.bpy.2014. 10.072

Videla, A. H. (2002). Prevention and control of biocorrosion. Int. Biodeterior. Biodegradation 49, 259-270. doi: 10.1016/S0964-8305(02)00053-7

Watanabe, M., Suzuki, Y., Sasaki, K., Nakashimada, Y., and Nishio, N. (1999). Flocculating property of extracellular polymeric substance derived from a marine photosynthetic bacterium, Rhodovulum sp. J. Biosci. Bioeng. 87, 625-629. doi: 10.1016/S1389-1723(99)80125-X

Wimpenny, J., Manz, W., and Szewzyk, U. (2000). Heterogeneity in biofilms. FEMS Microbiol. Rev. 24, 661-671. doi: 10.1111/j.1574-6976.2000.tb00565.x

Wirtanen, G., Salo, S., Allison, D. G., Mattila-Sandholm, T., and Gilbert, P. (1998). Performance evaluation of disinfectant formulations using poloxamer-hydrogel biofilm-constructs. J. Appl. Microbiol. 85, 965-971. doi: 10.1111/j.1365-2672. 1998.tb05260.x

Young, K. D. (2006). The selective value of bacterial shape. Microbiol. Mol. Biol. Rev. 70, 660-703. doi: 10.1128/MMBR.00001-06

Conflict of Interest Statement: The authors declare that the research was conducted in the absence of any commercial or financial relationships that could be construed as a potential conflict of interest.

Copyright (c) 2017 Bas, Kramer and Stopar. This is an open-access article distributed under the terms of the Creative Commons Attribution License (CC BY). The use, distribution or reproduction in other forums is permitted, provided the original author(s) or licensor are credited and that the original publication in this journal is cited, in accordance with accepted academic practice. No use, distribution or reproduction is permitted which does not comply with these terms. 